\title{
O ENSINO DE LITERATURA CONTRA A RECLUSÃO DA PALAVRA
}

\author{
Maria Fernanda Britto Rezende ${ }^{1}$
}

\begin{abstract}
Resumo: este trabalho é uma tentativa de estabelecer conexões entre a falta de liberdade vivida por professores e alunos e a violência escolar. Mais precisamente, partindo de textos teóricos como os de Theodor Adorno (1995) e Florestan Fernandes (1966), pretende abordar algumas das dificuldades de se ensinar literatura em meio a uma civilização técnica, assim como a falta de liberdade que perpassa os vários âmbitos da instituição escolar; em especial, no que toca os textos canônicos e o próprio trabalho dos professores em sala de aula (e o compromisso ético que eles devem ter frente a isso).
\end{abstract}

Palavras-chave: ensino de literatura, cânone, violência escolar

Abstract: this work is an attempt to establish connections between the lack of freedom experienced by teachers and students and school violence. More precisely, considering the works from Theodor Adorno (1995) and Florestan Fernandes (1966), it aims to address some of the difficulties of teaching literature in a technological civilization, and the lack of freedom that pervades the educational institution. It also discusses the work of teachers in the classroom with canonical texts, and the ethical commitment that they must have with their students.

Keywords: literature teaching, literary canon, school violence

\section{Introdução ${ }^{2}$}

A violência nasce da palavra emparedada.

Claude Colombier

Nos últimos anos, intensificou-se no Brasil o aumento no número de vagas em escolas e universidades, iniciado em meados da década de 70 . Segundo os dados da Pesquisa Nacional por Amostra de Domicílios (PNAD) de 2012, 98,2\% das crianças de 6 a 14 anos frequentavam a escola; para os jovens de 15 a 17 anos, a taxa de escolarização no mesmo período foi de

\footnotetext{
${ }^{1}$ Graduanda em Letras - Português e Latim na Universidade de São Paulo - USP. E-mail: mfbrezende@gmail.com.

${ }^{2}$ Este trabalho consiste em uma atividade realizada para a disciplina FLC0601 - Ensino de literatura brasileira, ministrada pelo Prof. Jaime Ginzburg, do DLCV-FFLCH-USP, no primeiro semestre letivo de 2014.
} 
$84,2 \%$, superior à de 2011 (83,7\%). Tal salto em quantidade, porém, não necessariamente tornou-se um salto em qualidade: os índices de evasão escolar são altos, e a taxa de analfabetismo permanece expressiva, sendo de $24,4 \%$ para aquelas pessoas de 60 anos ou mais. Isso é reflexo de uma sociedade excludente, que padece de profunda desigualdade social, assim não cumprindo o que determina a Constituição Federal.

A escola não só reverbera discursos presentes no meio social, mas também produz discursos e saberes que podem ser introjetados pelos alunos. Em uma sociedade voltada para o lucro e para o consumo, a escola muitas vezes torna-se um local em que a criatividade, o lúdico e o prazer estético não são encorajados. É um processo educacional autoritário, que busca o controle do conhecimento; não se propõe a reflexão por parte do aluno, mas sim que ele passivamente assimile aquilo que Ihe for passado. E a sociedade brasileira não é exceção a esse processo, também produzindo um ensino excludente de discursos, de debates, de conflitos. De formas de vida, enfim. E tal silêncio permite que as salas de aula tornem-se cenários para a violência, em suas múltiplas formas de manifestação.

Este trabalho é uma tentativa de estabelecer conexões entre a falta de liberdade vivida por professores e alunos e a violência escolar. Mais precisamente, pretendo abordar as dificuldades de se ensinar literatura em meio a uma civilização técnica, assim como a falta de liberdade que perpassa os vários âmbitos da instituição escolar; em especial, no que toca os cânones e o próprio trabalho dos professores em sala de aula (e o compromisso ético que eles devem ter frente a isso). Por fim, é também uma tentativa de entender minha própria experiência como aluna, visto que sofri bullying durante alguns anos, e essa experiência afetou profundamente (e negativamente) a minha vida.

\section{Discussão teórica}

Em seu artigo "Tabus acerca do magistério", publicado em 1965, Theodor Adorno discorre a respeito do problema da aversão em relação à docência. Sua experiência é a de que os universitários alemães recém- 
formados "sentem seu futuro como professores como uma imposição, a que se curvam apenas por falta de alternativas". (1995, p. 97) Segundo ele, há muitos motivos para tal antipatia, em especial as motivações materiais (por exemplo, os baixos salários) e as inconscientes (como as diferentes imagens de professor que circulam pela sociedade), sendo estas últimas as que analisará em pormenor.

Adorno elenca várias imagens de professor presentes nos discursos da época, como a do "professor autoritário", a do "professor submisso", a do "professor infantil". Essas imagens, apesar de opostas, não se excluem. Para explicá-las, o autor faz um apelo ao inconsciente histórico, em que a imagem do professor como um serviçal é influenciada por referências de professores como escravos, surgidas desde a Idade Média. Adorno acredita que os docentes (em especial, os primários) exercem um comportamento subalterno em razão de seus péssimos salários. Tal problema é muitas vezes a justificativa que encontram para descarregar suas frustrações em cima dos alunos, tornando-se professores autoritários.

Nesse contexto de uma sociedade capitalista, a relação entre 0 professor e seu ofício não é mais uma relação entre pessoas, mas sim uma relação entre coisas. Os professores alemães se tornaram vendedores de conhecimento; eles, assim como seu trabalho, se transformaram em mercadoria, e passaram a ser valorizados de acordo com seus (baixos) salários. A sociedade, dessa maneira, vê os professores de modo subalterno, e consideram que o conhecimento não tecnológico (em especial o das áreas de Artes e Humanidades) é de baixo valor. O trabalho humano torna-se tão descartável quanto os objetos de compra.

Além das pressões materiais, os docentes sofrem também pressões externas em relação a como devem agir em seu ofício. O senso-comum diz que os professores devem ser totalmente equilibrados e que não devem demonstrar emoções e afetividade em sala de aula. Já se naturalizou a imagem de um professor dogmático, mecânico, que apenas transmite conhecimento, e tal imagem muitas vezes não é posta em discussão. Isto não deveria acontecer, pois entre professor e aluno existe uma interação entre 
pessoas, não mercadorias. Tais pressões causam sofrimento ao docente, que corre o risco de colapso.

Portanto, para Adorno, é importante do ponto de vista da sociedade que a escola "[...]se conscientize do pesado legado de representações que carrega consigo" (1995, p. 117), para que, dessa maneira, seja possível uma mudança no comportamento dos professores. Entre elas, está a necessidade de aprendizado psicanalítico para o magistério, de maneira que os docentes tenham condições de pensarem-se a si mesmos em relação às pressões que os cercam. Além disso, ele defende a importância da dimensão afetiva na relação entre professores e alunos, pois é uma relação, antes de tudo, entre seres humanos.

Muito embora haja uma distância espacial e temporal considerável entre o ensaio de Adorno e a situação do professorado brasileiro, é de impressionar a atualidade dos fenômenos descritos pelo autor há quase cinco décadas. No Brasil de 2014, também temos professores desmoralizados, em posição subalterna, recebendo salários muito baixos e pressões externas; a desvalorização do conhecimento e do ofício de professor, equiparados a mercadorias; a falta de autoestima e a insegurança profissional dos docentes, que podem se tornar a base para um comportamento agressivo destes em relação aos alunos. Nesse sentido, análises psicanalíticas e sociais como as feitas por Adorno tornam-se fecundas para explicar tais problemas.

Em relação aos professores de literatura, Leahy-Dios encontra problemas semelhantes aos vistos por Theodor Adorno, assim como questões mais específicas enfrentadas pelos docentes desta área de conhecimento. Diz ela (2000, p. 203):

Professores de literatura no Brasil têm dificuldade, acima de tudo, em mediar a realidade da sala de aula e a educação literária academicista; têm um imenso problema com o cânone, imposto por um poder que eles não ousam confrontar[...] Mas também têm um sério problema consigo mesmos, como profissionais de literatura: sentem que não detêm um cabedal de leitura suficiente, estão insatisfeitos com os programas, os conteúdos, as escolas, os alunos, as provas, sua própria competência. 
A questão do cânone no ensino de literatura é bastante expressiva da desigualdade e dos conflitos presentes em nossa sociedade, pois está intimamente relacionada às estruturas de poder. De acordo com Roberto Reis (1992, p. 70), "Nas artes e na literatura, [...]cânon significa um perene e exemplar conjunto de obras - os clássicos, as obras-primas dos grandes mestres - um patrimônio da humanidade [...]a ser preservado para as futuras gerações, cujo valor é indisputável". Tal conjunto de artistas e obras deve ser considerado a melhor expressão da imagem dominante de uma nação ou de sociedade, deixando de fora representações e discursos que questionem estes padrões conservadores e a estabilidade de valores.

O cânone (assim como a própria noção de literatura) é proposto de maneira a abstrair as obras de suas circunstâncias históricas, como se os textos tivessem um valor intrínseco, sustentado por si mesmo. Este valor só será notado por aqueles poucos que detiverem a "chave de leitura" do texto, negando assim a polissemia inerente das obras literárias. O cânone ainda está vinculado a uma homogeneidade de conhecimento, excluindo os discursos que não sejam compatíveis com o que defendem as estruturas arcaicas da sociedade. Desta maneira, o cânon também faz parte das relações injustas que dividem o meio social, pois o conhecimento, que deveria ser libertação, tornase uma amarra, uma mercadoria acessível somente aos que podem pagar por ela.

Um dos espaços que detém o poder de determinação daquilo que é verdadeiro e aceitável é justamente a universidade, onde é ensinada a leitura das grandes obras, reafirmando o cânone e criando um círculo vicioso: os vestibulares pedem a leitura das obras canônicas; as escolas e cursinhos preparam o alunado para decorar os estereótipos de leitura, já estabelecidos pela convenção; e as editoras, por sua vez, investem no mercado do cânone, reforçando os mesmos textos e as mesmas leituras de sempre. Assim sendo, os alunos acabam perdendo a noção da pluralidade de significados dos textos literários, como se os discursos não tivessem mobilidade, como se o mundo não tivesse conflitos. 
A manutenção de discursos e poderes arcaicos pode ser explicada pela estrutura conservadora da sociedade brasileira, que se espraia inclusive pela área escolar. De acordo com Florestan Fernandes (1996, p. 86),

"O nosso sistema escolar ainda se organiza sob o imperativo
de servir a tendências predominantemente conservantistas,
mobilizando apenas uma fração dos recursos educacionais do
ambiente: aquela que se relaciona com a necessidade de
preservar a ordem estabelecida e, com ela, a posição que já
conquistamos na fruição dos bens daquela civilização."

Ou seja, a escola funciona como caixa de ressonância de disputas presentes no seio social, assim como introjeta nos alunos certos modos de ser e de pensar.

Para Roberto Reis (1992), a desconstrução deste processo ideológico seria o questionamento da própria canonização e os emaranhados do poder nos quais está envolvida. Leahy-Dios defende que essa discussão seja feita em sala de aula: segundo ela, somente com um ensino participativo, em que as vozes dos alunos sejam ouvidas, é que será possível haver um ensino verdadeiramente livre: "É difícil pensar em um meio melhor de problematizar conteúdos literários do que compartilhar o poder entre alunos e professores democraticamente na busca por interpretações significativas do artefato literário, oferecendo leituras variadas e de real significado multicultural." (2000, p. 205) Dessa forma, quando o professor assume as literaturas marginais, ou mesmo leituras diferentes do cânone, a estrutura de poder é deslocada.

Outra faceta dos problemas enfrentados pelos professores de literatura, que de certa maneira também se relaciona à questão do cânone, é o ensino de poesia em uma sociedade tecnológica como a nossa. Averbuck afirma a importância do ensino de poesia para crianças por desenvolver nos alunos a criatividade e a capacidade para resolver problemas reais, por meio da descoberta afetiva da linguagem. Ela defende que a escola assuma a responsabilidade de "desenvolver no aluno (leitor) sua habilidade para sentir a poesia, apreciar o texto literário, sensibilizar-se para a comunicação através do poético e usufruir da poesia como uma forma de comunicação com o mundo" (1985, p. 67). 
Além disso, segundo ela (1985, p. 69), a poesia

[...]auxilia a compreensão da comunicação do irracional e do incomunicável, funcionando como "antídoto" em uma civilização urbana e técnica. O desenvolvimento do gosto da beleza, de um gosto pelo ritmo, e o jogo da linguagem asseguram, assim, seu domínio e levam à consciência ao mesmo tempo liberadora e lúdica da linguagem, à descoberta de níveis da língua e do real.

Apesar da importância da sensibilidade na formação da cidadania, o que geralmente se vê nas escolas é justamente a anulação desta qualidade, fruto de uma visão utilitarista e pragmática da educação e da vida. Por meio de uma concepção técnica de ensino, a escola anula a criatividade e a afetividade dos alunos, formando adultos "racionais", "cartesianos", que "otimizam" seu tempo. O mais irônico é que o mercado de trabalho exige que os adultos sejam criativos, sem que no entanto tenham espaço para isso na escola. Averbuck lamenta que o ensino da poesia dificilmente seja efetuado, seja por falta de compreensão dos professores, seja pela dificuldade em aplicá-la nas salas de aula.

Essa dificuldade decorre também por conta da estrutura de poder de nossa sociedade. A poesia mexe com o que há de irracional e indizível, aquilo que é recalcado pelas ideologias dominantes e contrário à civilização racionalista. Ensinar poesia encontra uma hostilidade nesse contexto de tecnicização, pois a leitura de textos propõe a mudança do ponto de vista dos alunos, tornando-os mais críticos da situação em que se encontram. É por isso que o professor (em especial o de Ciências Humanas) representa nesse contexto um perigo para a sociedade, já que suas ideias e sua capacidade de transformação podem levar a mudanças sociais.

\section{Um vínculo entre a falta de liberdade e a violência na escola}

Um professor nunca vai ter liberdade completa em relação ao que vai fazer com seus alunos em sala de aula. Seu trabalho é condicionado por pressões vindas de todos os lados: a coordenação pedagógica da escola, a direção, administração, os pais dos alunos, os valores sociais dominantes. Tudo o que ele pode dizer e fazer deverá ser feito de acordo como que os outros pensam e querem, de maneira que o espaço público o respeite. Caso se 
desvie do que é considerado correto e verdadeiro, corre o risco de perder sua autoridade. Muito embora nossa sociedade não valorize os professores, vê sua força como uma ameaça ao status quo.

Nossa sociedade é marcada por conflitos, causados pela desigualdade social. Essa desigualdade é mantida para que a elite possa continuar com seus privilégios. Isso é feito por meio das ideias propagadas pela classe dominante, que, tornando-se senso comum, têm o efeito de eliminar a consciência das causas da desigualdade, promovendo o conformismo e resignação das classes pobres, naturalizando a pobreza. Portanto, as ideias propagadas aos pobres mantêm a desigualdade, enquanto eles não têm consciência de sua situação, aumentando sua fragilidade e sofrimento. E tudo isso é coberto pelo manto da fantasia de que a sociedade brasileira é estável e homogênea.

No final do século XIX e se acentuando a partir do pós-guerra, iniciou-se no Brasil um processo de modernização, trazendo tecnologia, urbanização e industrialização. O problema é que tais projetos trouxeram também heranças da política colonial. Isso criou uma contradição do sistema, pois, com uma base conservadora, não há mudanças, há o reforço da desigualdade. Especificamente em relação ao ensino, Florestan Fernandes (1966) demonstra preocupação com 0 aumento quantitativo das salas de aula sem 0 correspondente aumento de qualidade. Da mesma maneira, há uma modernização conservadora que molda a escola e a universidade, tornando-as elitistas e imediatistas, reduzindo sua capacidade criar ideias novas.

Essa é a política do cânone, utilizado como forma de controle social. A literatura tal como é posta institucionalmente se torna um empecilho para a mudança social; não cria condições concretas de democratização. Afinal, como diz Leahy-Dios (2000), muitas vezes os alunos não vêm importância no texto; têm dificuldades com a linguagem; precisam aprender em pouquíssimo tempo tudo o que cai na prova de vestibular; também podem ter seus próprios interesses desvalorizados, tornando o ensino árido e pouco empático. Se os textos não são envolventes, se são incompreensíveis e distantes dos alunos, 
então por que eles iriam se importar com isso? Por que iriam se importar com qualquer coisa?

A obrigação de seguir as leituras canônicas também é um fator de frustração para os professores. Nesse sentido, torna-se extremamente importante não só a introdução das leituras marginais em sala de aula, mas também a abordagem crítica do cânone, para que a leitura destes textos esteja em diálogo continuado com a cultura contemporânea e os problemas sociais. Ao abordar obras canônicas, é preciso ter uma estratégia de leitura que seja "capaz de fazer emergir as diferenças, em particular aquelas que conflitem com os sentidos que foram difundidos pela leitura canônica" (Reis, 1992, p. 77). De acordo com Leahy-Dios (2000, p. 204):

As questões de voz e representação nas aulas de educação literária no Brasil exigem uma revisão do cânone, dos programas de conteúdos e dos métodos didáticos que estão imbricados e tecidos na política do país. Dada a urgência dos assuntos socioculturais sobre questões como gênero e sexo, os alunos apontam claramente o tipo de herança cultural que o cânone literário deveria privilegiar, quando pedem a inclusão de autores e textos que lidem com eventos políticos recentes no país.

Tive um bom exemplo dessa revisão dos métodos didáticos em 2013, ao fazer estágio na Verde Que te Quero Verde, uma escola construtivista de São Vicente - SP. A professora de Língua Portuguesa do Ensino Fundamental II propôs aos alunos de 9ªno uma sequência didática sobre a poesia marginal, que incluía a leitura de uma coletânea de poemas de Paulo Leminski, Ana Cristina César, Cacaso e outros. Após a leitura, em duplas, os alunos tiveram de fazer pequenas encenações dos poemas; posteriormente, precisaram explicar oralmente o que haviam entendido dos textos. Também tiveram a chance de criar seus próprios poemas. A meu ver, foi uma sequência bem pensada e que deu certo, pois a maioria dos alunos ficou curiosa a respeito do assunto, se envolvendo afetuosamente com a poesia marginal.

A questão da representatividade do cânone (e da literatura em geral) é de extrema importância porque trabalha com a identidade dos alunos, seus valores e visão de mundo. Ao ter contato com a polissemia dos textos, os discentes podem estabelecer conexões entre a obra e sua realidade social, 0 
que pode proporcionar a eles mudanças de pensamento e comportamento. Além disso, o envolvimento afetivo com o texto pode desenvolver neles a criatividade e a empatia, essenciais para a construção da cidadania.

É preciso que isso se dê em um espaço de abertura para a opinião do outro, para o debate sadio. Se os textos não os envolvem, se não há espaço para a fala, esta negação pode desencadear atos de violência. A tese de Dos Santos (2001) vem ao encontro disso, já que afirma que a violência no espaço escolar é fruto do "enclausuramento do gesto e da palavra" em sala de aula (2001, p. 105). Ainda segundo ele, a violência seria a "relação social de excesso de poder que impede o reconhecimento do outro - pessoa, classe, gênero ou raça - mediante o uso da força ou da coerção, provocando algum tipo de dano, configurando o oposto das possibilidades da sociedade democrática contemporânea" (2001, p. 108).

Ou seja, a representatividade e legitimidade do cânone está intimamente envolvida com a questão da violência simbólica do saber escolar. As leituras dominantes não legitimam diferentes formas de sexualidade, de cultura, de gênero que não sejam as masculinas, brancas, europeias, heteronormativas, letradas. Com isso, os alunos não se sentem representados pelas leituras e podem introjetar os valores dominantes, dessa maneira não conseguindo aceitar diferentes maneiras de ver o mundo. Essa situação, unida às práticas pedagógicas agressivas (que nos são familiares, visto que nossas práticas atuais são legados de ditaduras), à falta de empatia e a competição entre estudantes pode levar a um cenário de violência e agressão, que decorre da falta de conexão afirmativa com o outro.

A pouca habilidade com a linguagem faz com que as pessoas muitas vezes se manifestem fisicamente de maneiras agressivas. Portanto, para mudar esse quadro, é preciso que ocorram mudanças na relação entre a escola, professores e alunos. Como defende Adorno (1995), os professores devem propiciar condições para que os alunos pensem sobre si mesmos em relação aos conteúdos, para que suas leituras façam sentido a eles. Também defende a inserção dos afetos no ensino, pois professor e alunos são seres 
humanos, que também têm limitações e sofrimentos que devem ser compreendidos.

É necessário também que, desde o primeiro momento, haja um espaço saudável para o debate, em que os alunos possam ouvir a opinião dos outros e ter suas falas ouvidas, consideradas e respeitadas, não sendo humilhados nem ridicularizados por sua exposição. Nesse sentido, a meu ver, aulas de literatura com debates sobre as obras literárias ajudariam muito, pois, além de desenvolver a sociabilidade dos alunos, desenvolveria neles também a habilidade com a linguagem e a empatia em relação aos outros. Segundo Dos Santos (2001, p. 110), é preciso

[...]desenvolver a possibilidade de falar mediante a instauração de lugares para as palavras, resgatando o sentido da linguagem, e a palavra tomando o lugar dos atos de violência. Para tanto, a escola precisaria expandir o saber escrever e dar condições para publicar, assegurando instrumentos que fazem da palavra e da escuta um poder. Ao mesmo tempo, esse diálogo, paciente, obstinado, pedagógico, instaura um respeito ao outro, com ações e sentimentos de reciprocidade que podem ajudar a eliminar a violência, construindo possibilidades do encontro. Esse aprendizado real da liberdade vivida no cotidiano, através de ações de ajuda mútua escolar, de relações com a vida associativa local e de reconhecimento do pluralismo cultural, no espaço escolar, afirmam uma primeira lição nas ações contra a violência na escola.

No início de 2014, trabalhei como tutora de latim na EMEF Amorim Lima, localizada na região do Butantã, em São Paulo - SP. O projeto pedagógico, baseado no projeto da Escola da Ponte, respeita o ritmo dos alunos, assim como seus interesses e possibilidades. Durante uma parte dos recreios, os alunos se reúnem em roda com suas tutoras, para que possam conversar sobre problemas de comportamento, avisos e outros assuntos. A comunidade e os pais têm ampla participação nos acontecimentos da escola, o que é muito positivo. Na Amorim, é visível o respeito aos alunos e a preocupação de que todos tenham um espaço seguro para falar e emitir suas opiniões. Essa abordagem não torna a escola isenta de problemas, evidentemente, mas melhora imensamente o convívio.

\section{Considerações finais}


Atualmente, enfrentamos na escola uma situação agônica; explicável por um histórico de desigualdade social e mudanças conservadoras. Frente a tantos problemas, uma mudança real em nossa sociedade parece impossível. Mas é preciso começar de algum lugar, e me parece que uma forte conviç̧ão dos professores de literatura sobre a importância do seu trabalho, assim como uma generosidade e ética em relação aos alunos, pode trazer condições para solucionar este problema. Um ato consciente de ruptura com regras normativas em favor de mudanças sociais e pedagógicas pode mudar uma realidade escolar.

Citando Paulo Freire, Cyana diz que "a educação não pode ser outra coisa que comunicação e diálogo" (2000, p. 204) O professor, portanto, deve considerar a diversidade de seus alunos, enxergando-os como seres humanos capazes de aprender e a expressar suas opiniões em um ambiente que propicie o diálogo, a inclusão, a empatia, o respeito, o debate sadio. Deve levar em conta também a polissemia dos textos e suas diferentes leituras, de maneira a permitir o despertar da lucidez do alunado e a transformação dos problemas do contemporâneo. Precisa trabalhar de modo que sua pedagogia não mais permita comportamentos repressores e agressivos, para que os alunos possam se tornar sensíveis em relação às outras pessoas, à linguagem e ao mundo. Mudanças que, como diz Florestan Fernandes (1966), só uma boa loucura proporcionaria. 


\section{Referências}

ADORNO, Theodor. Tabus acerca do magistério. In: Educação e emancipação. São Paulo: Paz e Terra, 1995.

AVERBUCK, Lígia. A poesia e a escola. In: ZILBERMAN, Regina, org. Leitura em crise na escola. Porto Alegre: Mercado Aberto, 1985. P. 63-83.

COLOMBIER, Claude et al . A violência na escola. São Paulo: Summus, 1989.

DOS SANTOS, José Vicente Tavares. A violência na escola: conflitualidade social e ações civilizatórias. Educação e Pesquisa, São Paulo, v.27, n.1, p. 105-122, jan./jun. 2001.

FERNANDES, Florestan. A crise do ensino. In: Educação e sociedade no Brasil. São Paulo: Edusp, 1966.

LEAHY-DIOS, Cyana. Conceituando dificuldade em educação literária. In:

Educação literária como metáfora social. Niterói: Ed. UFF, 2000.

PORTAL BRASIL. PNAD 2012: cai o percentual de pessoas sem instrução.

Disponível em: <http://www.brasil.gov.br/educacao/2013/09/pnad-2012-cai-opercentual-de-pessoas-sem-instrucao > Acesso em: 07 jun. 2014.

REIS, Roberto. Cânon. In: JOBIM, José Luís, org. Palavras da crítica. Rio de Janeiro: Imago, 1992. 